\title{
The Island Chumash
}


Long ago before there were white people here, a wizard at San Gabriel caused a great drought and famine that lasted for five years. María's grandfather Estévan and his wife lived through this period. This sorcerer had a tablet or stone on which he painted many figures of men and women bleeding from the mouth and falling down. He took this out into the hills and exposed it to the sun, praying for sickness. For five years there was no rain, and many people died of hunger. The seeds the women had stored came to an end, and there were no acorns or islay. Even the shells along the shore had only sand in them. When the men went out to get mescal only a few came back - the rest died of hunger-and the women put hot water on their breasts so they would have some milk to keep husbands or brothers alive. Finally some other sorcerers spied on the man who was causing all this and saw him going into the hills. When he returned they said, "Let's follow his tracks and see what he has been doing." They followed the tracks and found the tablet or whatever it was with the evil figures on it, and they threw it into the water. The drought ended and it rained. How did those people know how to do those things? They were wiser than the American in those days (Blackburn I975, 276). 


\section{The Island Chumash}

Twenty miles off the coast of southern California, a chain of four islands extends from east to west along the southern border of the Santa Barbara Channel-the northern Channel Islands (map I). People colonized the larger islands in this chain as early as 13,500 years ago and archaeological evidence indicates that they were permanently occupied by at least $7,500 \mathrm{BP} .{ }^{*}$ At the time of European contact (AD I542), island Chumash people were heavily dependent upon maritime resources, lived in relatively large coastal communities governed by chiefs, and had active exchange and marriage alliances with their relatives on the mainland coast (Johnson 1988, 2000; Kennett and Kennett 2000). Indeed, some archaeologists consider the people that lived on this section of the California coast to be among the most socially and politically complex hunter-gatherers in the world (Arnold 200I; Erlandson and Rick 2002a). The primary goal of this book is to explore the evolutionary history of these people with an emphasis on stability and change in subsistence and settlement strategies, economic intensification, competitive and cooperative behavior, and the ultimate development of the social and political complexity that was evident at historic contact.

Human behavioral ecology (HBE) provides the theoretical framework for studying cultural evolutionary processes in this maritime setting. As the Chumash myth in the epigraph suggests, the conditions

*All dates presented in this volume are calibrated year before present (BP). 


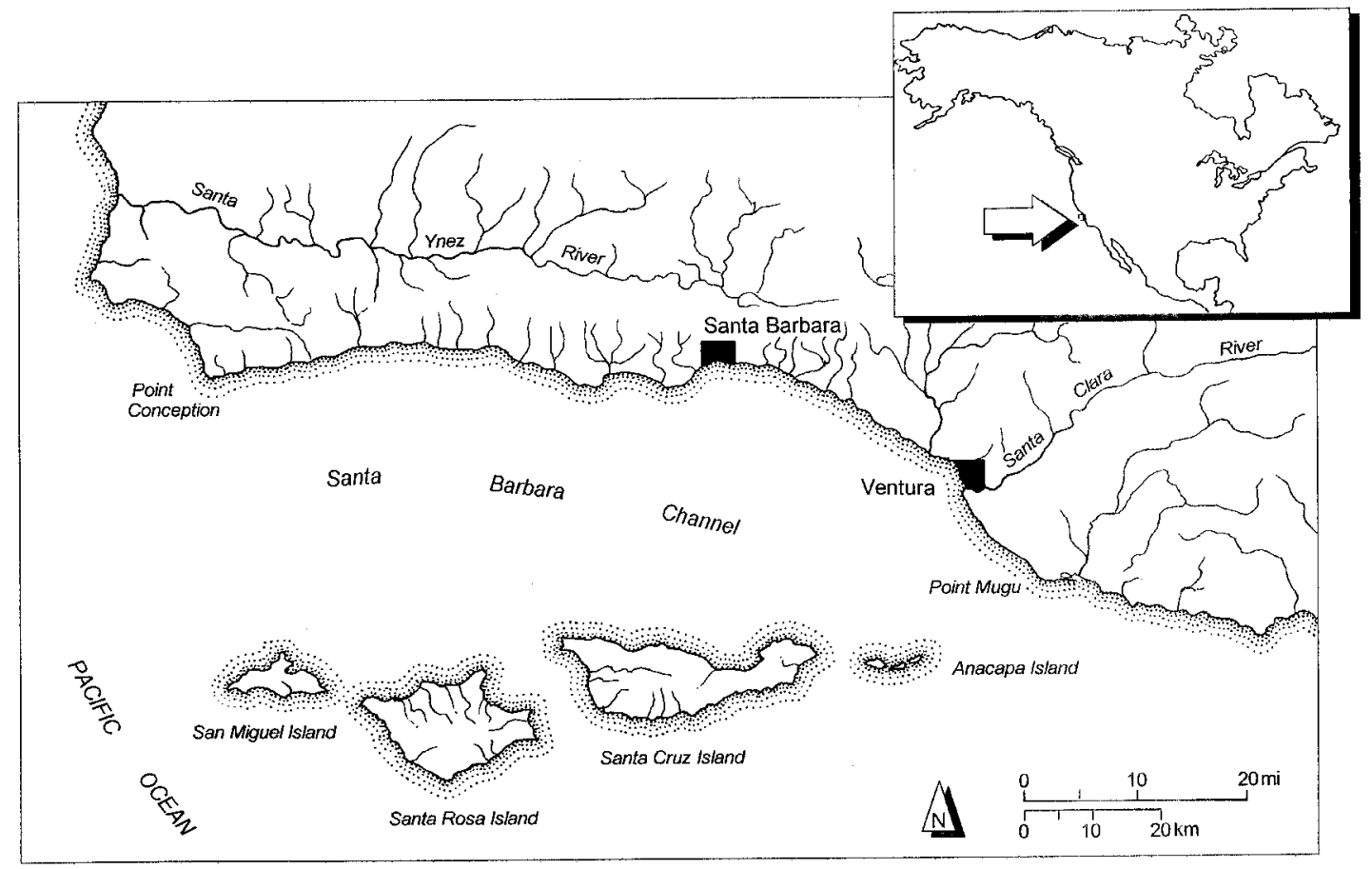

MAP I. Map of the northern Channel Islands and adjacent mainland (drafted by R. van Rossman). 
(both social and environmental) in the Santa Barbara Channel region were not constant through time and people were continually confronted with new situations that they had to contend with, and these decisions ultimately had strong evolutionary consequences. HBE is well equipped to explain behavioral variability and adaptive design within changing ecological contexts. * (Bettinger and Richerson I996; Smith and Winterhalder 1992; Winterhalder and Smith 1992, 2000). It is firmly grounded in neo-Darwinian principles, particularly natural selection theory, and furnishes an expanding set of models that can be tested with ethnographic or archaeological data within different environmental and social settings (Bettinger and Richerson 1996; Broughton and O'Connell 1999; Winterhalder and Smith 1992, 2000). During the past 20 years, HBE has provided a solid theoretical framework for studying human foraging behavior (Begossi 1992; Broughton 1994a, 1999; Madsen and Schmitt 1998; Smith 1991; Ugan and Bright 200I), and the repertoire of topics addressed has expanded to include various non-subsistence-related behaviors such as land tenure and the development of social and political hierarchies (see chapter 2).

Despite the success of HBE for exploring and explaining changes in human behavior, it is rarely used by archaeologists working in maritime settings (for exceptions see Broughton 1999; Hildebrandt and Jones 1992). This is partially related to the tendency for archaeologists to emphasize terrestrial resources and to discount the important role that maritime or aquatic habitats and resources played in the evolutionary history of our species (Pálsson 1988). Some archaeologists have even argued that aquatic resources were a "last resort" for foragers living in coastal settings, and the relatively late prehistoric use of these resources worldwide is often cited as evidence for their low value (Binford 1968; Osborn 1977; Pálsson 1988). This is inconsistent with ethnographic and archaeological evidence indicating that maritime environments supported some of the largest and most complex hunter-gatherer groups on earth (Erlandson 200I; Pálsson I988; Yesner 1980, 1987). Indeed, one study suggests that the fatty acids found in marine foods such as fish played an essential role in the early development of the human brain (Gibbons 2002) and that aquatic and maritime adaptations were important for the demographic and

*Ecological context is broadly defined here to include environmental, economic, social, and political contingencies. 
geographic expansion of anatomically modern humans after 150,000 years ago (Erlandson 200I). Nevertheless, archaeologists working in maritime settings are left in a theoretical vacuum without the tools necessary to explore cultural evolutionary processes. These processes are complex, and it is argued here that HBE is well positioned to fill this theoretical void.

\section{Study Area}

When Juan Rodríguez Cabrillo sailed into the Santa Barbara Channel in $\mathrm{AD}$ 1542, much of the Chumash population was concentrated along the mainland coast, but large numbers of people also lived on the northern Channel Islands. Ethnohistorical accounts indicate that they lived in large coastal villages, were heavily dependent upon fishing, produced a variety of trade items, and participated in an extensive interregional exchange network (Johnson 1988). The plank canoe was a vital innovation that was used for open ocean fishing and intervillage commerce (Arnold 1995; Gamble 2002). Food and nonfood items were exchanged between individuals living in coastal and island villages (King 1990). Islanders produced a variety of trade items, including shell beads that were considered a medium of exchange throughout Chumash territory (Arnold and Munns 1994; King 1990). Aspects of this exchange system were controlled by elite individuals who commanded some economic and political authority (Johnson 2000).

The evolutionary history of Chumash society is explored in this book based on the rich archaeological records on the northern Channel Islands of California. Studies suggest that some of these islands were colonized as early as 13,500 BP (Erlandson et al. 1996a, I996b; Johnson et al. 2000; Rick et al. 200Ia), providing the first evidence for human occupation of coastal habitats in North America (see Jones et al. 2002). The archaeological record clearly shows permanent occupation of all the larger Channel Islands by 7,500 years ago and suggests that many of the cultural traditions recorded in the area by Spanish explorers were well established by at least 650 years ago. In this book, I explore the emergence and dominance of the human behavior associated with these cultural traditions.

In a general sense, islands provide well-bounded areas to study cultural evolutionary processes and consequently have received much attention by archaeologists (Burley and Dickinson 200I; Keegan and 
Diamond 1987; Kirch 2000; Patton 1996). The offshore islands of California are particularly important because they contain the longest and best-preserved archaeological sequences available for study along the west coast of North America. Thanks to Channel Islands National Park and The Nature Conservancy, the islands are permanently protected from the urban sprawl that is impacting much of southern California's coastal landscape. Archaeological deposits are also relatively undisturbed compared with contemporary sites on the mainland because the pocket gopher (Thomomys spp.), an incessant burrower that mixes archaeological sequences (Erlandson I984), never colonized the Channel Islands. Well-preserved archaeological deposits and the long, continuous record of human occupation make the Channel Islands one of the best areas in western North America to study foraging strategies, adaptive variability, and evolutionary processes.

Although there are many benefits to studying prehistoric behavioral strategies on the northern Channel Islands, there are also some fundamental limitations, particularly when examining the late Holocene development of sociopolitical complexity. This is because the largest and most important villages (economically and politically) were positioned along the mainland coast where a confluence of key environmental variables promoted higher population levels (Erlandson I994). Because mainland archaeological sequences are relatively poorly preserved, the higher-resolution records of the northern Channel Islands are crucial as a proxy for what was occurring throughout the region. On the other hand, the behavioral strategies used by islanders during the Holocene cannot be decoupled from the opportunities and constraints imposed by economic and political developments that occurred more broadly in the region.

In this book, I synthesize environmental, ethnohistorical, and archaeological data from the northern Channel Islands collected during the past century (Arnold 1987, 200I; Colten I995, 200I; Erlandson 1994; Erlandson and Colten I991; Erlandson and Glassow 1997; Erlandson and Jones 2002; Gamble 2002; Gamble et al. 200I; Glassow I977, I980, I993a, 1997, 2000; Glassow and Wilcoxon I988; Heizer and Elsasser 1956; Johnson I982, I988, I993, 2000, 200I; King 1990; Perry 2003; Rick et al. 200Ia; Rogers 1929). These studies are augmented with my own sustained work on the islands since I993 (figure IA). The bulk of these data were collected during my Ph.D. research, and the data-gathering methods used are presented in greater detail elsewhere (Kennett I998). The study included surveys on Santa Cruz, Santa Rosa, and San Miguel islands 

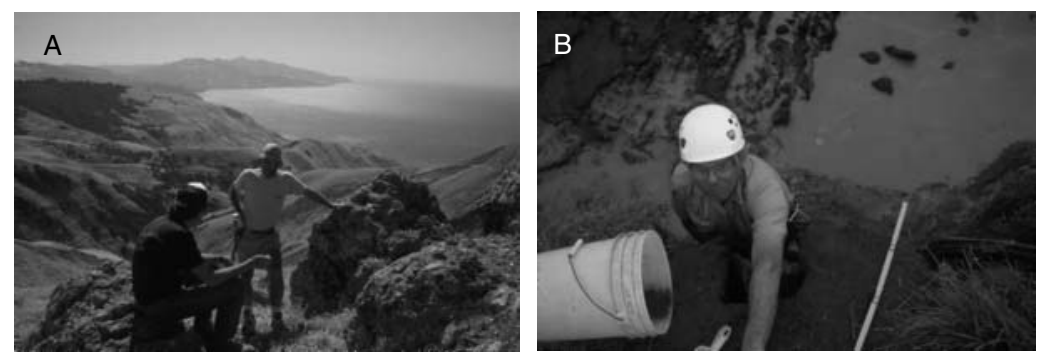

Figure I. (A) Photograph of Michael Glassow (left) and James Kennett (right) discussing the geologic context of chert microblade quarries on eastern Santa Cruz Island. Photo taken during the author's first visit to the northern Channel Islands in 1993 (photo by D. Kennett looking west across Santa Cruz Island). (B) Don Morris excavating column sample from seacliff exposure at CA-SRI-15, western Santa Rosa Island (photo by D. Kennett).

coupled with small-scale sampling of archaeological sites. Many of the samples were taken from wave-cut exposures in seacliffs to minimize the impact on these important archaeological deposits (figure IB). These data, along with published information on other islands sites $(\sim \mathrm{I}, 900$ sites), were incorporated into a digital spatial database (Geographic Information System or GIS) to explore changes in settlement location and land use through time. Artifact assemblages and radiocarbon dates were used to determine when sites were occupied. Quantitative analyses of faunal and tool assemblages provided information regarding changes in subsistence, technology, and social organization through time. Stable oxygen and carbon isotopic analyses of marine shells from key sites were used to determine the season of shellfish harvesting and to infer the duration and season of site use.

\section{Climate Change and Emergent Cultural Complexity}

Archaeological data indicate that socially and politically complex huntergatherer societies were well established on the southern California coast, including the northern Channel Islands, by at least 650 years ago. Archaeologists working in southern California have long suggested that changes in climate during the Holocene played an important role in the development of greater sociopolitical complexity (Arnold I987, I99I, I992a, I992b, I993, I997, 200I; Arnold et al. I997; Colten 1993, I994, 
I995; Erlandson I997a, 1997b; Glassow et al. I988, I994; Johnson 2000; Jones and Kennett 1999; Jones et al. 1999; Kennett 1998; Kennett and Kennett 2000; Lambert 1994, 1997; Lambert and Walker 1991). The exploration of climatic influences is not surprising given the quality of the available climatic and archaeological records and the relative sensitivity of the region to major climatic perturbations (Behl and Kennett 1996; Cannariato et al. 1999; Hendy and Kennett 1999, 2000; Heusser I978; Heusser and Sirocko 1997; Kennett and Ingram 1995a, I995b; Kennett and Kennett 2000; Pisias 1978, I979). Nevertheless, considerable debate has emerged about the details of the timing and nature of sociopolitical evolution on the southern California coast in relation to environmental change (Arnold 1992a; Arnold et al. 1997; Erlandson 2002a; Kennett 1998; King 1990; Raab and Bradford 1997; Raab and Larson 1997; Raab et al. 1995).

Central to this debate are the specific environmental and biotic changes that may have triggered sociopolitical and economic developments. In particular, this debate has focused on the relative roles of changing terrestrial and marine ecosystems on cultural development between 800 and 650 years ago (Arnold 1997; Arnold et al. 1997; Jones and Kennett 1999; Jones et al. 1999; Lambert 1997; Lambert and Walker I99I; Raab and Larson 1997). Arnold (I992a, 1997) and others (Arnold and Tissot 1993; Arnold et al. 1997; Colten 1993, 1994, 1995; Colten and Arnold 1998, 2000) have focused on sociopolitical and economic responses to marine and terrestrial climatic stresses on the northern Channel Islands, particularly a reported interval of elevated sea-surface temperature and low marine productivity between 800 to 650 years ago. Elevated sea-surface temperatures were inferred from a longstanding marine paleoclimatic sequence for the region and faunal assemblages from Santa Cruz Island (Arnold 1992b; Arnold and Tissot I993; Colten 1994, I995; Pisias 1978, 1979). In contrast, Raab and Larson (1997) suggested that punctuated cultural changes during this interval were stimulated by increasing violence and competition between individuals resulting from widespread drought and the associated reduction of terrestrial resources (also see Jones and Kennett 1999; Jones et al. I999; Kennett and Kennett 2000; Yatsko 2000).

This debate is considered within an evolutionary and ecological framework, informed by HBE, and in light of new paleoclimatic data for the region (Kennett and Kennett 2000). The paleoclimatic data are used to evaluate the environmental context for cultural stability and change during the Holocene. Most important, they indicate that the 
TABLE I. Chronology for Santa Barbara Channel region including northern Channel Islands

\begin{tabular}{lll}
\hline & \multicolumn{1}{c}{ BC-AD } & \multicolumn{1}{c}{ BP } \\
\hline Terminal Pleistocene & BC 11,000-8000 & $13,000-9,950$ \\
Early Holocene & BC 8000-6120 & $9,950-8,060$ \\
Early Period & BC 6120-490 & $8,060-2,440$ \\
Middle Period & BC 490-AD 1150 & $2,440-800$ \\
Late Middle Period & AD 660-980 & $1,290-970$ \\
Middle/Late Transition & AD 1150-1300 & $800-650$ \\
Late Period & AD 1300-1782 & $650-168$ \\
Historic & AD 1782- & $168-$ \\
\hline
\end{tabular}

SOURCES: Arnold 1992a; Erlandson and Colten I99I; Kennett I998; King 1990.

interval from 800 to 650 years ago, prior to the dominance of sociopolitical complexity in the region, was marked by noticeably cool, highly variable marine conditions associated with high marine productivity. These new paleoenvironmental data are interpreted along with broad patterns of cultural evolution during the Holocene (I0,000 to 650 years ago), including increasing population levels, intensified fishing, and decreased settlement mobility. A behavioral-ecological model is proposed for the emergence of sociopolitical complexity that emphasizes competitive and cooperative responses to strong climatic variability, including sustained terrestrial drought and high marine productivity that mark the interval between 1,500 to 650 years ago. Larger and more sedentary settlements emerged on the northern Channel Islands during this period in the context of increased regional violence (Lambert 1994, I997; Lambert and Walker 199I). Violence was exacerbated by the introduction of the bow and arrow sometime between I,500 and I,300 years ago. Islanders responded to these highly unstable environmental and social conditions in unique ways, competing violently for available resources in some cases and apparently cooperating in others. Reduced settlement mobility, intensified fishing, and the production of exchange items emerged as alternative strategies for dealing with environmental and social instability. Cooperative strategies, such as trade, associated with the new economic system became dominant after 650 years ago as violent interaction decreased regionally. It is within this context that certain individuals were able to enhance their social status and at times control aspects of the political and economic relationships for their own benefit. The basis for this hypothesis is outlined in this volume. 
The ages in this study (table I) are expressed as calibrated calendar years before present $(\mathrm{BP})$. This is somewhat unconventional in the study of Channel Islands prehistory where calendar years BC/AD or radiocarbon years before present are commonly used. The decision to use calibrated calendar years before present was largely driven by the broad use of this dating system by paleoclimatologists and the belief that the use of a religious calendrical system is inappropriate within this particular context. A more detailed description of the chronology is presented in chapter 4 , but table I summarizes the chronological framework used in this study with cross-references between $\mathrm{BP}$ and $\mathrm{BC} / \mathrm{AD}$ dates. 